\title{
Indikasi dan Keterampilan Resusitasi Jantung Paru (RJP)
}

\author{
Kaliammah Ganthikumar \\ Program Studi Pendidikan Dokter, Fakultas Kedokteran Universitas Udayana \\ (kaliammah kumar@yahoo.com)
}

Diterima: 10 Maret 2016. Disetujui: 5 April 2016. Diterbitkan: Juni 2016

\begin{abstract}
ABSTRAK
Resusistasi Jantung Paru adalah suatu teknik yang sangat berguna untuk menyelamatkan nyawa dalam keadaan darurat, termasuk serangan jantung atau hamper tenggelam, di mana napas seseorang atau detak jantung telah berhenti. The American Heart Assosiation merekomendasikan bahwa setiap orang atau tenaga medis harus memulai RJP dengan penekanan dada. Walaupun, seseorang kekurang ilmu pengetahuan atau pengalaman apabila melakukan penekanan dada pada seseorang henti napas atau henti dettak jantung ia dapat menyelamatkan nyawa organ tersebut. Hal ini jauh lebih baik daripada tidak melakukan apa-apa. RJP dapat tetap menjaga aliran oksigen yang adekuat ke otak dan organ vital lainnya sampai ia dapat memulihkan denyut jantung normal. Apabila, seseorang kekurangan oksigen dalam darah ia akan menyebabkan kerusakan jaringan otak yang permenen dalam beberapa menit. Kekurangan oksigen dalam waktu delapan sampai sepuluh menit dapat menyebabkan kematian.
\end{abstract}

Kata Kunci: Teknik RJP, RJP pada henti jantung

\section{ABSTRACT}

Cardiopulmonary resuscitation (CPR) is a livesaving technique which is very useful in many emergencies, such as heart attack or near drowning, in which someone's breathing or heartbeat has stopped.The American Heart Association recommends that everyone - doesn't have experience or medical personnel can start CPR with chest compression. Chest compression can help to save someone's life eventhough you doesn't have knowledge. Its better then doing nothing. CPR can delivery enough oxygen to brain and vital organ till definitive medication is given to restore normal heart rthym. The supply of oxygen to brain is distupted for eight to te minutes can cause death.CPR for a cardiac arrest I starting from circulation then breathing then airway( $C-B-A)$

Keyword: Technique CPR, CPR for cardiac arrest

\section{PENDAHULUAN}

Resusitasi jantung paru (RJP) adalah metode untuk mengembalikan fungsi pernapasan dan sirkulasi pada pasien yang mengalami henti napas dan henti jantung yang tidak diharapkan mati pada saat itu. Tindakan RJP ini tidak hanya berlaku dalam ruangan operasi, tapi dapat juga diluar jika terdapat suatu kejadian dimana ada seorang pasien atau korban, dalam usaha mempertahankan hidupnya dalam keadaan mengancam jiwa. Hal ini dikenal dengan Bantuan Hidup Dasar (BHD) atau Basic Life Support (BLS). Sedangkan bantuan yang dilakukan dirumah sakit sebagai lanjutan dari BHD disebut Bantuan Hidup Lanjut atau Advance Cardiac Life Support (ACLS). ${ }^{1}$ Basic life support atau bantuan hidup dasar (BHD) adalah pendekatan sistemik untuk penilaian pertama pasien, mengaktifkan respon gawat darurat. BHD sangat bermanfaat bagi penyelamatan kehidupan mengingat dengan pemberian sirkulasi dan napas buatan secara sederhana. BHD memberikan asupan oksigen dan sirkulasi darah ke sistem tubuh terutama organ yang sangat vital dan sensitif terhadap kekurangan oksigen seperti otak dan jantung. Berhentinya sirkulasi beberapa detik sampai beberapa menit, asupan oksigen ke dalam otak terhenti, terjadi hipoksia otak yang yang mengakibatkan 
kemampuan koordinasi otak untuk menggerakkan organ otonom menjadi terganggu, seperti gerakan denyut jantung dan pernapasan. 1,2,3

Penyelamatan ini akan sangat bermanfaat jika dilakukan dengan mungkin dan sebaik mungkin. Lebih baik ditolong, walupun tidak sempurna daripada dibiarkan tanpa pertolongan. Pada saat henti napas, kandungan oksigen dalam darah masih tersedia sedikit, jantung masih mampu mensirkulasikannya ke dalam organ penting, terutama otak, jika pada situasi diberi bantuan pernapasan, kebutuhan jantung akan oksigen untuk metabolisme tersedia dan henti jantung dapat dicegah. ${ }^{1,2,3}$

Resusitasi jantung paru (RJP) yang efektif adalah dengan menggunakan kompresi dan dilanjutkan dengan ventilasi. Tindakan ini dapat dilakukan oleh orang awam dan juga orang yang terlatih dalam bidang kesehatan. Keadaan yang perlu perhatian dan dapat menyebabkan Systemic Cardiopulmonary Arrest (SCA) adalah seperti kecelakaan, sepsis, kegagalan respiratori, dan banyak lagi. Pada saat pertama kali menemukan pasien atau korban penilaian dini harus dilakukan. Jika dalam penilaian ditemukan sumbat jalan nafas, tidak ditemukan adanya nafas dan tidak ada nadi maka tindakan BHD harus dilakukan dengan segera. ${ }^{3,5}$

Menurut American Heart Association (AHA), rantai kehidupan mempunyai hubungan erat dengan resusitasi jantung paru, karena penderita yang diberikan RJP, mempunyai kesempatan yang besar untuk dapat hidup kembali. RJP yang digunakan dirujuk kepada pedoman dari AHA yaitu 2010 American Heart Association Guidelines for Cardiopulmonary Resuscitation and Emergency Cardiovascular care. ${ }^{4,5}$

\section{DEFINISI}

Resusitasi Jantung Paru (RJP) atau Cardiopulmonary Resusitasi (CPR) adalah upaya mengembalikan fungsi nafas dan atau sirkulasi yang berhenti oleh berbagai sebab dan boleh membantu memulihkan kembali kedua-dua fungsi jantung dan paru ke keadaan normal. Bantuan hidup dasar (BHD) atau basic life support (BLS) termasuk mengenali jika terjadinya serangan jantung, aktivasi respon sistem gawat darurat, dan defibrilasi dengan menggunakan defibrillator. ${ }^{2,3}$

\section{TUJUAN}

Tujuan Bantuan Hidup Dasar (BHD) ialah oksigenasi darurat yang diberikan secara efektif pada organ vital seperti otak dan jantung melalui ventilasi buatan dan sirkulasi buatan sampai paru dan jantung dapat menyediakan oksigen dengan kekuatan sendiri secara normal. Hal ini adalah untuk mencegah berhentinya sirkulasi darah atau berhentinya pernapasan. Resusitasi mencegah terjadinya berhentinya sirkulasi atau berhentinya respirasi yang dapat menyebabkan kematian selsel akibat dari kekurangan oksigen dan memberikan bantuan eksternal terhadap sirkulasi melalui kompresi dada (chest compression) dan ventilasi dari korban yang mengalami henti jantung atau henti nafas. 3,5

\section{INDIKASI MELAKUKAN RJP}

\section{Henti Nafas}

Henti nafas primer (respiratory arrest) dapat disebabkan oleh banyak hal, misalnya serangan stroke, keracunan obat, tenggelam,inhalasi asp/uap/gas, obstruksi jalan nafas oleh benda asing, tesengat listrik, tersambar petir, serangan infrak jantung, radang epiglottis, tercekik (suffocation), trauma dan lain-lainnya. ${ }^{1}$

Henti nafas ditandai dengan tidak adanya gerakan dada dan aliran udara pernafasan dari korban dan ini merupakan kasus yang harus dilakukan tindakan Bantuan Hidup Dasar (BHD). Pada awal henti nafas, jantung masih berdenyut dan nadinya masih teraba, dimana oksigen masih dapat masuk ke dalam darah untuk beberapa menit dan jantung masih dapat mensirkulasikan darah ke otak dan organ-organ vital yang lainnya. Dengan memberikan bantuan resusitasi, ia dapat membantu menjalankan sirkulasi lebih baik dan mencegah kegagalan perfusi organ. ${ }^{3,5}$

\section{Henti Jantung}

Henti jantung primer (cardiac arrest) adalah ketidaksanggupan curah jantung untuk memenuhi kebutuhan oksigen keotak dan organ vital lainnya secara mendadak dan dapat balik normal, jika dilakukan tindakan yang tepat atau akan menyebabkan kematian atau kerusakan otak menetap kalau tindakan tidak adekuat. Henti jantung yang terminal akibat usia lanjut atau 
penyakit kronis tertentu tidak termasuk henti jantung atau cardiac arrest. ${ }^{2}$

Sebagian besar henti jantung disebabkan oleh fibrilasi ventrikel atau takikardi tanpa denyut, kemudian disusun oleh ventrikel asistol dan terakhirnya oleh disosiasi elektro-mekanik. Dua jenis henti jantung yang berakhir lebihsulit ditanggulangi kerana akibat gangguan pacemaker jantung. Fibirilasi ventrikel terjadi karena koordinasi aktivitas jantung menghilang. ${ }^{34}$

Henti jantung ditandai oleh denyut nadi besar yang tidak teraba (karotis, femoralis, radialis) disertai kebiruan (sianosis), pernafasan berhenti atau gasping, tidak terdapat dilatasi pupil karena bereaksi terhadap rangsang cahaya dan pasien tidak sadar. Pengiriman oxygen ke otak tergantung pada curah jantung, kadar hemoglobin $(\mathrm{Hb})$, saturasi $\mathrm{Hb}$ terhadap oxygen dan fungsi pernapasan. Iskemia melebihi 3-4 menit pada suhu normal akan menyebabkan kortek serebri rusak menetap, walaupun setelah itu dapat membuat jantung berdenyut kembali. ${ }^{5}$

\section{SISTEM PERNAFSAN DAN SIRKULASI}

Tubuh manusia terdiri dari beberapa sistem, diantara sistem yang utama adalah sistem pernafasan dan sistem sirkulasi. Kedua-dua sistem ini, merupakan komponen utama yang memainkan peranan penting untuk mempertahankan hidup. Jika terganggunya salah satu fungsi dari sistem ini, ini dapat mengakibatkan ancaman kehilangan nyawa. Tubuh dapat menyimpan makanan untuk beberapa minggu dan menyimpan air untuk beberapa hari, tetapi hanya dapat menyimpan oksigen $\left(\mathrm{O}^{2}\right)$ untuk beberapa menit saja. ${ }^{1,3}$

Sistem pernafasan memberikan pasokan oksigen kedalam tubuh sesuai dengan kebutuhan dan juga mengeluarkan karbondioksida (CO2). Sistem sirkulasi inilah yang bertanggungjawab memberikan pasokan oksigen dan nutrisi keseluruh jaringan tubuh. Diantara komponenkomponen yang berhubungan dengan sirkulasi adalah jantung, pembuluh darah yang terdiri dari artery, vein, dan capillary, serta darah dan komponen-komponennya. ${ }^{3}$

Dalam sistem sirkulasi, jantung berfungsi untuk memompa darah dan kerjanya sangat berhubungan erat dengan sistem pernafasan. Pada umumnya, semakin cepat kerja jantung berlaku, semakin cepat pula frekuensi pernafasan dan sebaliknya. Terdapat banyak sebab jantung dapat berhenti bekerja antaranya penyakit jantung, gangguan pernafasan, syok, penurunan kesadaran, dan komplikasi penyakit lain,seperti stroke. ${ }^{5}$

2.5 BANTUAN HIDUP DASAR (BHD)

Bantuan hidup dasar (BHD) atau basic life support (BLS) ialah oksigenasi darurat yang diberikan secara efektif pada organ vital seperti otak dan jantung melalui ventilasi buatan dan sirkulasi buatan sampai paru dan jantung dapat menyediakan oksigen dengan kekuatan sendiri secara normal. Untuk dapat mengingat dengan mudah tindakan pada BHD ini dirumuskan dengan huruf $A, B$ dan C iaitu : ${ }^{234}$

$\begin{array}{lll}\text { A } & \text { airway } & \text { (jalan nafas) } \\ \text { B } & \text { breathing } & \text { (bantuan nafas) } \\ \text { C } & \text { circulation } & \text { (bantuan sirkulasi) }\end{array}$

\section{RESUSITASI JANTUNG PARU (RJP)}

Sebelum melakukan tahapan A (airway) terlebih dahulu dilakukan prosedur awal pada korban, yaitu memastikan situasi dan keadaan pasien aman atau tidak dengan memanggil nama atau sebutan Pak!!!, Bu!!!!, Mas!!!, Mbak!!!, dll yang umum dengan keras disertai menyentuh atau menggoyangkan bahu dengan mantap, sambil memanggil namanya. Prosedur ini disebut sebagai teknik "touch and talk". Hal ini cukup untuk membangunkan orang tidur atau merangsang seseorang untuk bereaksi. Jika tidak ada respon, kemungkinan pasien tidak sadar. Terdapat tiga derajat tingkat kesadaran, yaitu, sadar penuh, setengah sadar, dan tidak sadar. Sadar penuh yang bererti pasien dalam keadaan sadar, berorientasi baik terhadap diri, waktu dan tempat, setengah sadar yang bererti pasien mengantuk atau bingung, manakala pasien tidak sadar bererti pasien tidak ada apa-apa respon. ${ }^{1,5}$

Jika pasien berespon tinggalkan pada posisi dimana ditemukan dan hindari kemungkinan resiko cedera lain yang bisa terjadi dan analisa kebutuhan tim gawat darurat. Jika sendirian, tinggalkan pasien sementara, mencari bantuan. Observasi dan kaji ulang secara regular. Jika pasien tidak berespon berteriak minta tolong. Kemudian atur posisi pasien, sebaiknya pasien terlentang pada permukaan keras dan rata. Jika ditemukan 
tidak dalam posisi terlentang, terlentangkan pasien dengan teknik log roll, secara bersamaan kepala, leher dan punggung digulingkan. Atur posisi untuk penolong. Berlutut sejajar dengan bahu pasien agar secara efektif dapat memberikan resusitasi jantung paru (RJP). ${ }^{5}$

Terakhirnya, nadi karotis diperiksa. Menurut AHA Guideline 2010 tidak menekankan pemeriksaan nadi karotis sebagai mekanisme untuk menilai henti jantung karena penolong sering mengalami kesulitan mendeteksi nadi. Jika dalam lebih dari 10 detik nadi karotis sulit dideteksi, kompresi dada harus dimulai. Penolong awam tidak harus memeriksa denyut nadi karotis. Anggap cardiac arrest jika pasien tiba-tiba tidak sadar, tidak bernapas atau bernapas tapi tidak normal (hanya gasping). ${ }^{5}$

\section{A (Airway)}

Pastikan jalan nafas terbuka dan bersih yang memungkinkan pasien dapat bernafas.

\section{Pemeriksaan Jalan Nafas}

Untuk memastikan jalan nafas bebas dari sumbatan karena benda asing. Bila sumbatan ada dapat dibersihkan dengan tehnik cross finger ( ibu jari diletakkan berlawan dengan jari telunjuk pada mulut korban). Cara melakukan tehnik cross finge adalah pertama sekali silangkan ibu jari dan telunjuk penolong. Kemudian, letakkan ibu jari pada gigi seri bawah korban dan jari telinjuk pada gigi seri atas. Lakukan gerakan seperti menggunting untuk membuka mulut korban. Akhirnya, periksa mulut setelah terbuka apakah ada cairan,benda asing yang menyumbat jalan nafas. $^{5}$

\section{Membuka Jalan Nafas}

Pada korban yang tidak sadar tonus otot menghilang, maka lidah dan epiglotis akan menutup faring dan laring sehingga menyebabkan sumbatan jalan nafas. Keadaan ini dapat dibebaskan dengan tengadah kepala topang dahi (Head tild Chin lift) dan manuver pendorongan mandibula (Jaw thrush manuver). Cara melakukan teknik Head tilt chin lift (gambar 1a) ialah letakkan tangan pada dahi korban,kemudian tekan dahi sedikit mengarah ke depan dengan telapak tangan penolong. Letakkan ujung jari tangan lainnya dibawah bagian ujung tulang rahang korban. Tengadahkan kepala dan tahan serta tekan dahi korban secara bersamaan sampai kepala pasien/korban pada posisi ekstensi. Manakala, cara untuk melakukan teknik jaw thrust manuvere (gambar 1b) adalah letakkan kedua siku penolong sejajar dengan posisi korban. Kemudian, kedua tangan memegang sisi kepala korban. Penolong memegang kedua sisi rahang dan kedua tangan penolong menggerakkan rahang keposisi depan secara perlahaan. Akhirnya, pertahankan posisi mulut korban tetap terbuka. ${ }^{1,5}$

Apabila terdapat benda asing yang mengobstruksi jalur nafas pasien,ia dikeluarkan. Kemudian cek tanda kehidupan iaitu respon dan suara napas pasien. Jangan mendongakkan dahi secara berlebihan, secukupnya untuk membuka jalan napas saja, karena pasien boleh ada cedera leher. ${ }^{2,5}$

Menurut AHA Guideline 2010 merekomendasikan untuk gunakan head tilt-chin lift untuk membuka jalan napas pada pasien tanpa ada trauma kepala dan leher. Sekitar 0,12-3,7\% mengalami cedera spinal dan risiko cedera spinal meningkat jika pasien mengalami cedera kraniofasial dan/atau GCS <8. Manakala, gunakan jaw thrust jika suspek cedera servikal. Pada pasien suspek cedera spinal lebih diutamakan dilakukan restriksi manual (menempatkan 1 tangan di ditiap sisi kepala pasien) daripada menggunakan spinal immobilization devices karena dapat mengganggu jalan napas tapi alat ini bermanfaat mempertahankan kesejajaran spinal selama transportasi. $^{5}$ 
(a)
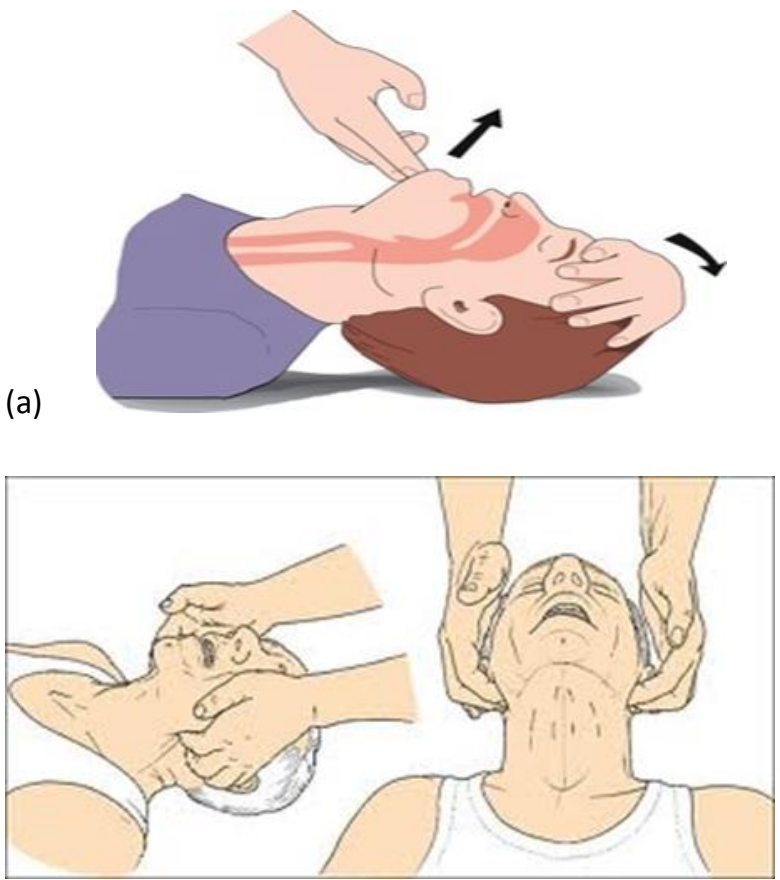

(b)

Gambar 1. Pembebasan Jalan Nafas (a) teknik

Head tilt chin lift dan (b) tehnik jaw thrust manuver. ${ }^{4}$

\section{B (BREATHING)}

Breathing terdiri dari 2 tahap iaitu :

A) Memastikan korban tidak bernafas atau tidak.

Dengan cara melihat pergerakan naik turunya dada (look), mendengar bunyi nafas (listen) dan merasakan hembusan nafas (feel), dengan teknik penolong mendekatkan telinga diatas mulut dan hidung korban sambil tetap mempertahankan jalan nafas tetap terbuka. Ini dilakukan tidak lebih dari 10 detik (gambar 2). ${ }^{5}$

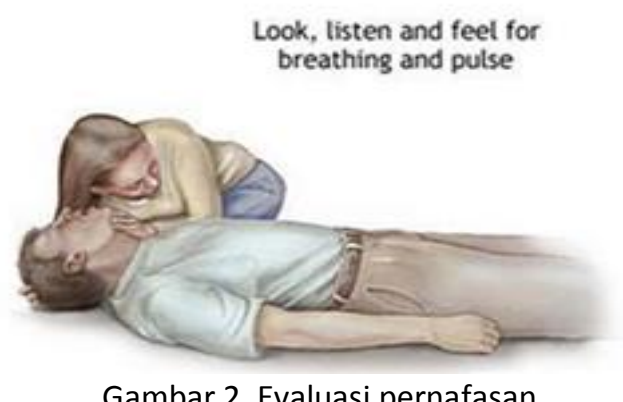

B) Memberikan bantuan nafas

Bantuan nafas dapat dilakukan melalui mulut ke mulut, mulut ke hidung, mulut ke stoma (lubang yang dibuat pada tenggorokan). Bantuan nafas diberikan sebanyak 2 kali, waktu tiap kali hembusan $1,5-2$ detik. $^{5}$
1. Mulut ke mulut

Merupakan cara yang cepat dan efektif. Pada saat memberikan penolong tarik nafas dan mulut penolong menutup seluruhnya mulut pasien/korban dan hidung pasien/korban harus ditutup dengan telunjuk dan ibu jari penolong.Volume udara yang berlebihan dapat menyebabkan udara masuk ke lambung. ${ }^{5}$

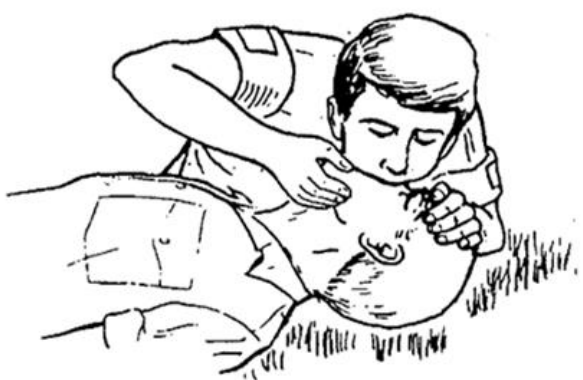

Gambar 3. Pemberian nafas dari mulut ke mulut

2. Mulut ke hidung

Direkomendasikan bila bantuan dari mulut korban tidak memungkinkan,misalnya korban mengalami trismus atau luka berat. Penolong sebaiknya menutup mulut korban pada saat memberikan bantuan nafas. ${ }^{5}$

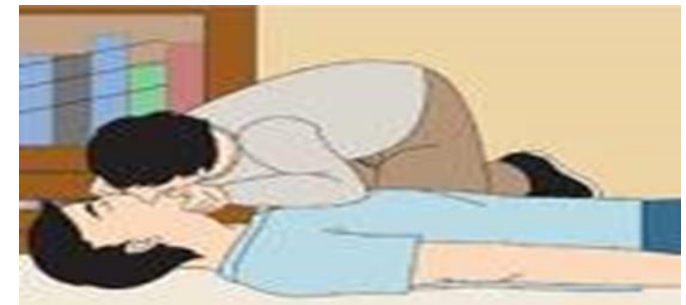

Gambar 4. Pernafasan dari mulut ke hidung

\section{Mulut ke stoma}

Dilakukan pada korban yang terpasang trakheostomi atau mengalami laringotomi. (gambar5). ${ }^{5}$

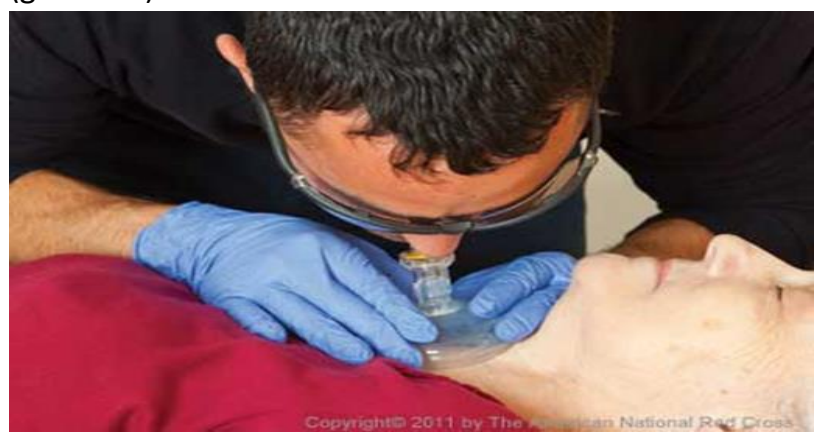

Gambar 5. Pernafasan mulut ke stoma 


\section{C (CIRCULATION)}

Nilai sirkulasi darah korban dengan menilai denyut arteri besar (arteri karotis, arteri femorsalis). Berikut merupakan langkah-langkah RJP iaitu : ${ }^{3,5,6}$

1. Apabila terdapat denyut nadi maka berikan pernafasan buatan 2 kali

2. Apabila tidak terdapat denyut nadi maka lakukan kompresi dada sebanyak 30 kali.

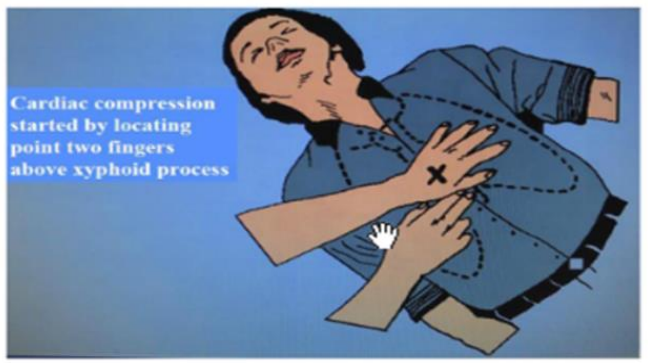

Gambar 6. Posisi tangan pada kompresi dada

3. Posisi kompresi dada, dimulai dari melokasi processus xyphoideus dan tarik garis ke kranial 2 jari diatas processus xyphoideus dan lakukan kompresi kepada tempat tersebut (gambar 6).

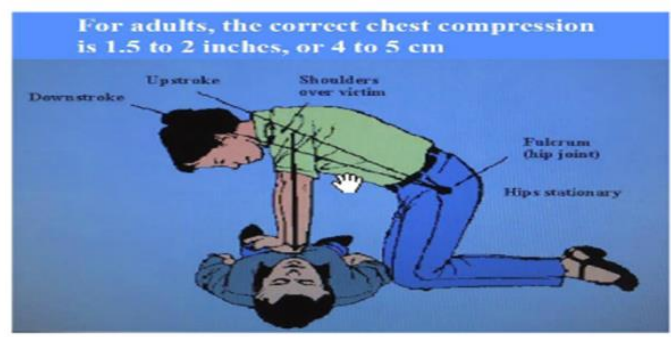

Gambar 7. Posisi penolong pada kompresi dada

4. Kemudain berikan 2 kali nafas buatan dan teruskan kompresi dada sebanyak 30 kali. Ulangi siklus ini sebanyak 5 kali dengan kecepatan kompresi 100 kali permenit. (gambar 7)

5. Kemudian check nadi dan nafas korban apabila :

a) Tidak ada nafas dan nadi: teruskan RJP sampai bantuan datang.

b) Terdapat naditetapi tidakan nafas : mulai lakukan lakukan pernafasan buatan.

c) Terdapat nadi dan nafas : korban membaik.

\section{SPESIFIK PENOLONGAN YANG DAPAT MEMBERIKAN RJP}

1. Penolong yang tidak terlatih (Untrained lay rescuer)Untuk orang awam yang tidak berpengalaman hanya kompresi dada yang dilakukan. ${ }^{5}$

2. Penolong yang terlatih (Trained lay rescuer) harus memberikan kompresi dada untuk pasien yang SCA dan dapat memberikan ventilasi dengan maka perbandingan $30: 2{ }^{5}$

3.Penyedia pelayan kesehatan (Healthcare Provider). ${ }^{5}$

Resusitasi yang diberikan tergantung kasus yang dihadapi. Jika ada pasien yang lemas ataupun yang mempunyai obstruksi jalan pernapasan dan mengalami penurunan kesadaran, CPR juga dapat diberikan dengan kompresi dada sebanyak 30 kali dan diteruskan dengan ventilasi. Jika menemukan pasien yang tidak responsif atau tidak bernafas, asumsi SCA selalu dilakukan. 


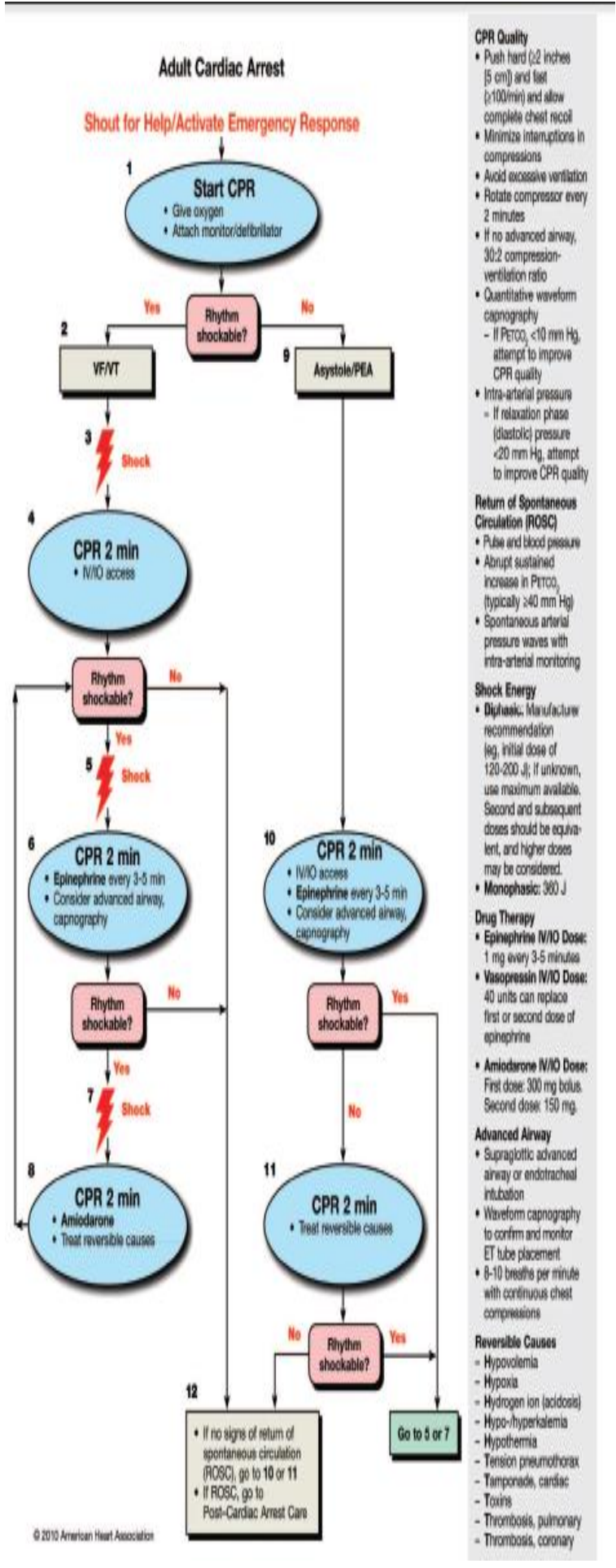

menunggu pengobatan lanjutan. Bantuan hidup lanjut dengan pemberian obat-obatan untuk memperpanjang hidup. Resusitasi dilakukan pada korban infark jantung, serangan stroke, keracunan obat, tenggelam,inhalasi asp/uap/gas, obstruksi jalan nafas oleh benda asing, tesengat listrik, tersambar petir, serangan infrak jantung, radang epiglottis, tercekik (suffocation),yang masih memberikan peluang untuk hidup.

Henti nafas primer (respiratory arrest) dapat disebabkan oleh banyak hal, misalnyaProsedur RJP terbaru adalah kompresi dada 30 kali dengan 2 kali napas buatan iaitu kecepatan 100 kali permenit. Penanganan dan tindakan cepat pada resusitasi jantung paru khususnya pada kegawatan kardiovaskuler amat penting untuk menyelematkan hidup, untuk itu perlu pengetahuan RJP yang tepat dan benar dalam pelaksanaannya.

\section{DAFTAR PUSTAKA}

1. American Heart Association.2010.Part 4 Adult Basic Life Support in Circulation Journal

2. Subagjo A, Achyar, Ratnaningsih E, sugiman $T$, Kosasih A,Agustinus R.2011.Bantuan Hidup Jantung Dasar BSCL Indonesia.Edisi 2011.Jakarta: Perhimpunan Dokter Spesialis Kardiovaskular Indonesia ( PERKI)

3. Wiryana IM, Sujana IBG,Sinardja K, Budiarta IG. Buku Ajar IImu Anestesia dan Reanimasi. Jakarta: Indeks.2010

4. Latief S.A. Petunjuk Praktis Anestesologi. Edisi kedua. Penerbit FKUI. Jakarta.2010

5. Miller RD.Anestesia, 5th ed.Churcill Livingstone. Philadelphia.2000.

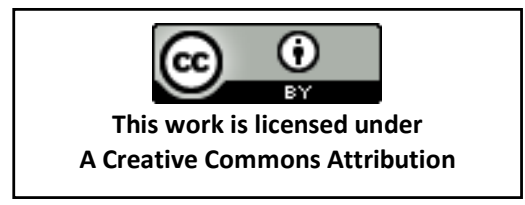

\section{SIMPULAN}

Resusitasi mengandung arti harfiah "menghidupkan kembali" tentunya dimaksudkan usaha-usaha yang dapat dilakukan untuk mencegah suatu episode henti jantung berlanjut menjadi kematian biologis. Bantuan Hidup Dasar (BHD) atau Basic Life Support (BLS) bertujuan dengan cepat mempertahankan pasokan oksigen ke otak, jantung dan alat-alat vital lainnya sambil 